\title{
ARKEOLOGI KEPULAUAN MALUKU
}

Archaeology of Moluccas Archipelago

\author{
Lucas Wattimena \\ Balai Arkeologi Ambon \\ J1. Namalatu - Latuhalat, Ambon 97118 \\ lucas.wattimena@yahoo.com
}

Naskah diterima: 09-01-2013; direvisi: 08-03-2013; disetujui: 10-05-2013

\begin{abstract}
Archaeological cultural resources in the Maluku Islands consist of a variety of aspects, including Prehistoric, Historic, Islamic, colonial and Ethnoarchaeology. These aspects are categorized in helping the mapping of archaeological research in the Maluku Islands. Functional structural archaeological remains integrated in the cultural unity of the social system as a symbolic interaction. Maluku Archipelago covers thetwo areas, namely Maluku and North Maluku. The problem this paper is how archaeological resources can show the interpretation of symbolic interaction. Archaeological remains (cultural resources); dolmen, caves, castles, old country / old settlement, menhirs, sultanate, Kapata / folklore is the basic structure of cultural understanding in the Maluku Islands. The goal is to know and understand the remains, archaeological remains were able to reconstruct the culture of human society Maluku Islands. Approach to research using library study. From the research that archaeological cultural resources is a symbolic interpretation of the interaction of a group of human society in a particular area. Sites sampled studies prove that archaeological cultural resources as a reflection of the people of Maluku Generally and certain areas in the Moluccas in particular.
\end{abstract}

Keywords: Archaeology Resources, Structure, Moluccas Islands

\begin{abstract}
Abstrak
Sumberdaya budaya arkeologi di Kepulauan Maluku terdiri dari berbagai aspek, diantaranya Prasejarah, Sejarah, Islam, Kolonial dan Etnoarkeologi. Aspek-aspek tersebut dikategorisasikan untuk memudahkan pemetaan penelitian arkeologi di Kepulauan Maluku. Struktural fungsional tinggalan-tinggalan arkeologi terintegrasi dalam kesatuan sistem sosial budaya sebagai interaksi simbolik. Kepulauan Maluku berarti kita berbicara dalam dua wilayah, yaitu Maluku dan Maluku Utara. Permasalahan penulisan ini adalah bagaimana sumberdaya budaya arkeologis dapat menunjukan interprestasi interaksi simbolik. Tinggalan-tinggalan arkeologis (sumberdaya budaya); dolmen, gua, benteng, negeri lama/permukiman lama, menhir, kesultanan, kapata/folklore adalah struktur dasar pemahaman akan kebudayaan di Kepulauan Maluku. Tujuannya adalah untuk mengetahui dan memahami tinggalantinggalan arkeologis mampu merekonstruksi kebudayaan masyarakat manusia Kepulauan Maluku. Pendekatan penelitian menggunakan studi kepustakaan. Dari hasil penelitian bahwa sumberdaya budaya arkeologi merupakan suatu interprestasi interaksi simbolik suatu kelompok manusia masyarakat pada daerah tertentu. Situssitus kajian penulis yang menjadi sampel membuktikan bahwa sumberdaya budaya arkeologi sebagai cerminan masyarakat Maluku Umumnya dan daerah tertentu di Maluku pada khususnya.
\end{abstract}

Kata Kunci : Sumberdaya Arkeologi, Struktur, Kepulauan Maluku 


\section{PENDAHULUAN}

Kepulauan Maluku sudah dikenal sejak dahulu kala, ketika bangsa penjajah datang menjajah dan bahkan sebelumnya telah didatangi oleh orang-orang Arab, Cina yang melakukan perjalanan untuk perdagangan. Proses mulai awal Maluku dikenal sampa sekarang ini telah melalui berbagai lapisan masa sosial budaya yang merepresentasikan dinamika sosial budaya masyarakatnya sendiri secara holistik. Penduduk asli Maluku merupakan para imigran yang memasuk wilayah ini dari arah barat (Huliselan, 2009 : 4). Kepulauan Maluku, NTT, Sulawesi, Filipina termasuk dalam kelompok Wallacea, berada di antara paparan-paparan darata Sahul dan Sunda (Belwood, 2000 : 1-5).

Dengan demikian karakteristik arkeologi Kepulauan Maluku berbed dengan daerah-daerah lainnya di Indonesia. Secara territorial lebih kepada arkeologi kepulauan, dengan ciri dan karakteristik masyarakat manusia kepulauan. Adat istiadat yang ada dalam suatu kelompok masyarakat menjadi substansi integral identitas kelompok masyarakat tertentu. Masyarakat Maluku dikatakan sebagai masyarakat Maluku karen ada adat istiadat yang membungkus serta sifatnya kontiniusitas, tanpa meninggalkan substansi integral masyarakat manusia Maluku. Sumberdaya arkeologi yang ada di Maluku sangat banyak, bahkan ada juga yang belum ditelusuri. Diantara sumberdaya arkeologi yang ada, yaitu : pemukiman kuno/ negeri lama, megalitik/ dolmen, batu meja, benteng, kapata, budaya tutur. Kesemuannya ini merupakan struktur dasar sumberdaya arkeologi di Maluku yang inheren dengan sosial budaya orang Maluku secara holistik Tetapi satu yang pasti sosial budaya pasti akan mengalami perubahan baik secara cepat maupun lambat.

Tulisan ini mencoba memberikan gambaran bagaimana sumberdaya arkeolog yang ada di Kepulauan Maluku menjad struktur dasar kebudayaan masyarakat itu sendiri, dimana hasil sumberdaya budaya arkeologis dapat menunjukan interprestas interaksi simbolik. Tujuan dari pada tulisan tentang arkeologi di Kepulauan Maluku (Maluku dan Maluku Utara). Tinggalan arkeologi Kepulauan Maluku menjadi struktur dasar bagian dari khasanah gagasan, ide manusia dan budaya masa lampau. Interaks simbolik, maksudnya adalah tiap tinggalan arkeologi berinteraksi secara simbolik dengan sifat holistik atas kebudayaan itu sendiri.

\section{METODE}

Metode penelitian menggunakan studi pustaka dari hasil penelitian-penelitian arkeologi yang telah dilakukan. Studi pustaka dilakukan kepada hasil penelitian 5 tahun (2008-2012). Penelusuran pendekatan studi pustaka melalui hasil sesuai spesialisasi tema penelitian di wilayah kerja Balai Arkeologi Ambon, yaitu Prasejarah, Sejarah, Islam, Kolonial dan Etnoarkeologi.

Sejak berdiri pada tahun 1996 Balai Arkeologi Ambon telah melakukan penelitian sesuai dengan wilayah kerjanya, yakn Maluku dan Maluku Utara. Sebagai instans Pemerintah pusat di daerah (Unit Pelaksana Teknis Pusat) Balai Arkeologi Ambon telah memiliki 7 orang peneliti dengan berbagai bidang keahlian, diantaranya : Arkeologi prasejarah, Islam, Kolonial, Sejarah dan Etnoarkeologi.

Dalam rangka acuan konseptua penulisan menggunakan kerangka pikir sebagai acuan konteks peta pemikiran penulisan tersebut. Di bawah ini merupakan kerangka pikir penulis dalam menelaah penulisan tersebut, dimana keseluruhan konteks dasar struktur isi dari penulisa ini adalah bagaimana Kepulauan Maluku (Maluku dan Maluku Utara) sebagai propins di Indonesia Timur memiliki keanekaragaman sumberdaya budaya arkeologi. Tinggalan arkeologi di Kepulauan Maluku secara eksplisit dikatakan sebagai interprestas simbolik (pemaknaan), artinya dari berbagai tinggalan arkeologi telah memberikan pemknaan kepada manusia pendukungnya.

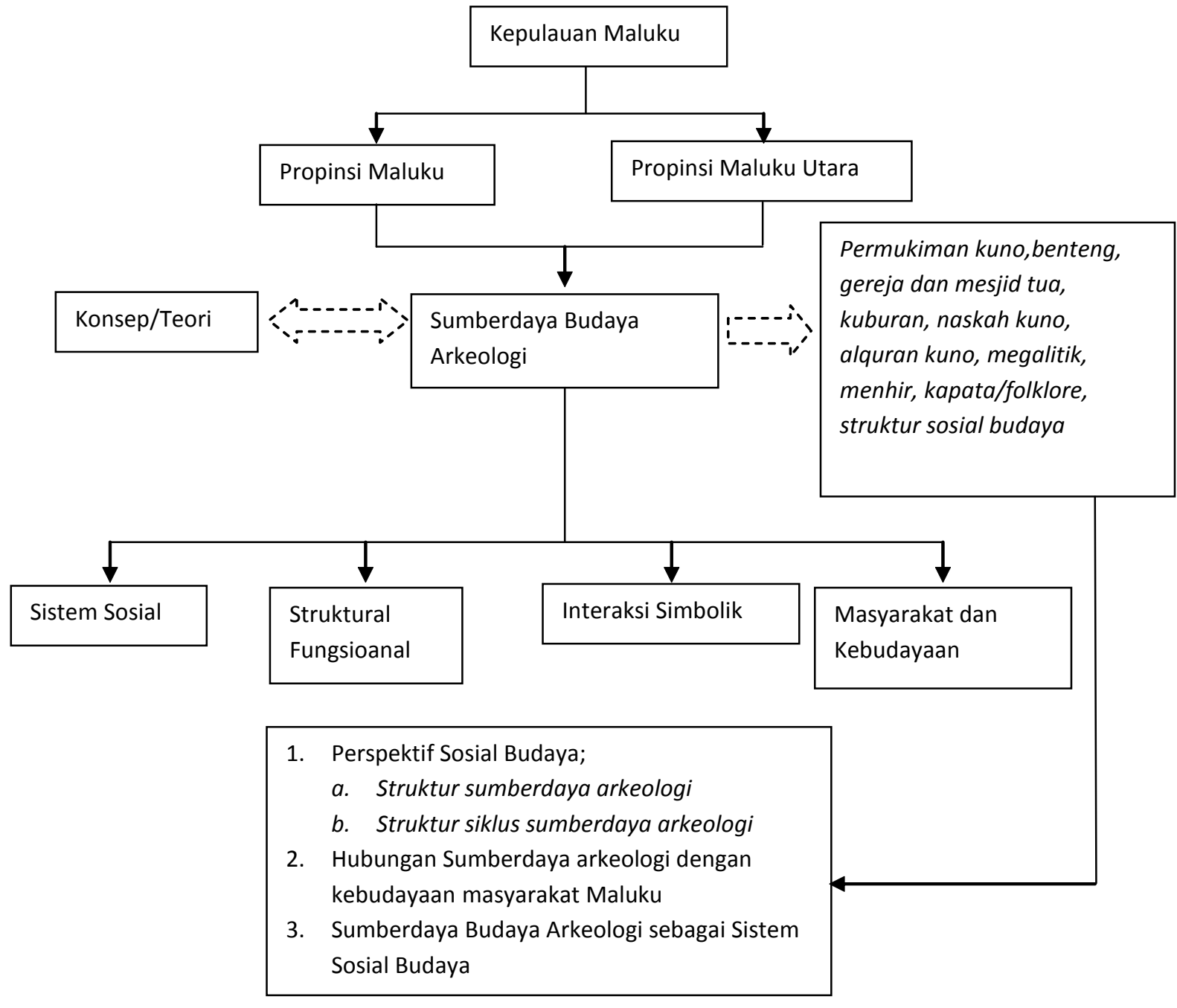

Gambar 1. Kerangka Pikir

Menurut Munandar (2010), kajian arkeologi yang mempelajari artefak masa silam, masalah mendasar yang harus diargumentasikan dalam pengungkapan makna adalah bagaimana teknik untuk memahami makna yang tersimpan dalam suatu objek artefaktual (Munandar, 2010: 85). Sementara itu, gambaran tinggalan arkeologi perahu batu di Kepulauan Maluku Tenggara sebagai tinjauan awal agar masyarakat memahami interprestasi dari simbol perahu tersebut, yaitu ideologi yang menampilkan ragam identitas komunal suatu bangsa tertentu (Ririmase, 2011 : 1-17).

\section{HASIL DAN PEMBAHASAN} Struktur Sumberdaya Arkeologi di Kepulauan Maluku

Radcliffe Brown menyebutkan bahwa struktur sosial adalah hubungan antara individu satu dengan yang lain. Bentuk struktur adalah abstraksi yang lebih tinggi, yaitu posisi yang ditempati. Hubungan fungsional adalah bagian dari organisasi sosial yang memungkinkan struktur sosia bekerja. Oleh sebab itu tatanan sumberdaya budaya merupakan suatu rangkaian struktur yang utuh, tertata oleh sistem sosial budaya. Misalnya sumberdaya budaya permukima kuno, dolmen (batu meja) kedua tinggala arkeologis ini secara kongkritifitas budaya 
satu kesatuan yang utuh. Sebab hubungan keduanya bersifat temporal parsial (Koentjaraningrat, 1987 : 172-184).

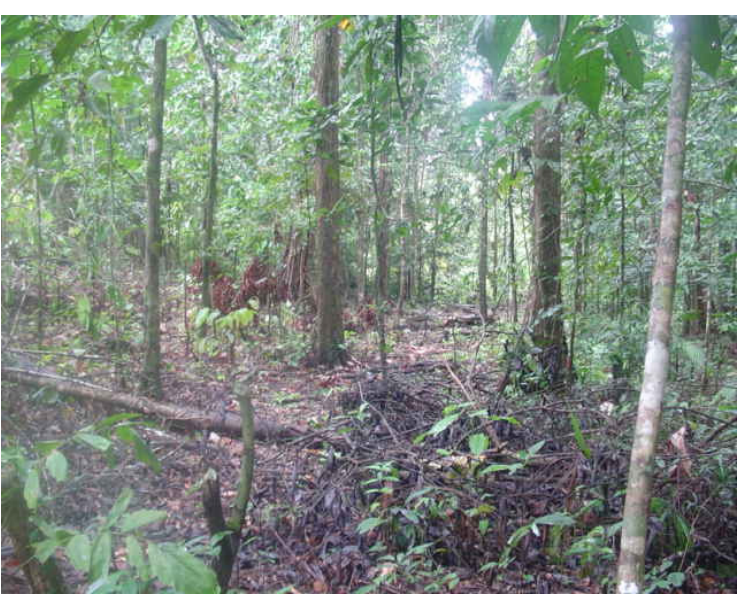

Gambar 2. Kampung Lama Situs Huhule,

Desa Tuhaha, Kec. Pulau Saparua, Kab. Maluku Tengah, Propinsi Maluku

(Sumber: Dokumen Bahi Arkeologi Ambon, 2008)

Pemukiman lama/negeri lama dan dolmen (batu meja), bagi masyarakat Maluku, khususnya Maluku Tengah sangat rat kaitannya. Setiap akan melakukan acara pelantikan Raja, calon Raja harus mengunjungi disana batawana dan melakukan tarian makumaku. Tujuan daripada hal tersebut adalah tidak lain untuk memperkenalkan calon aja kepada para leluhur, dengan maksud agar calon raja dapat memimpin negeri/desa dengan baik, jujur dan tidak sembarangan. Oleh Sunarningsih disebutkan bahwa manusia adalah makhluk individu bergantung pada alam sekitar atau lingkungan. Sebaga makhluk manusia bergantung pada manusia lainnya untuk memenuhi kebutuhan hidupnya. Kedua sifat manusia tersebut menyebabkan dalam kehidupan lebih memilih untuk hidup berkelompok, pada akhirnya manusia dapa menguasai teknologi pembuatan tempa tinggal dan dimulainya kehidupan menetap. Oleh sebab itu hubungan manusia dengan alam direpresentasikan lewat tradisi-tradisi berlanjut, dimana batu meja dolmen dijadikan sebagai benda bendawi dipergunakan dari masa ke masa (Latifundia, $2007: 25$ ).

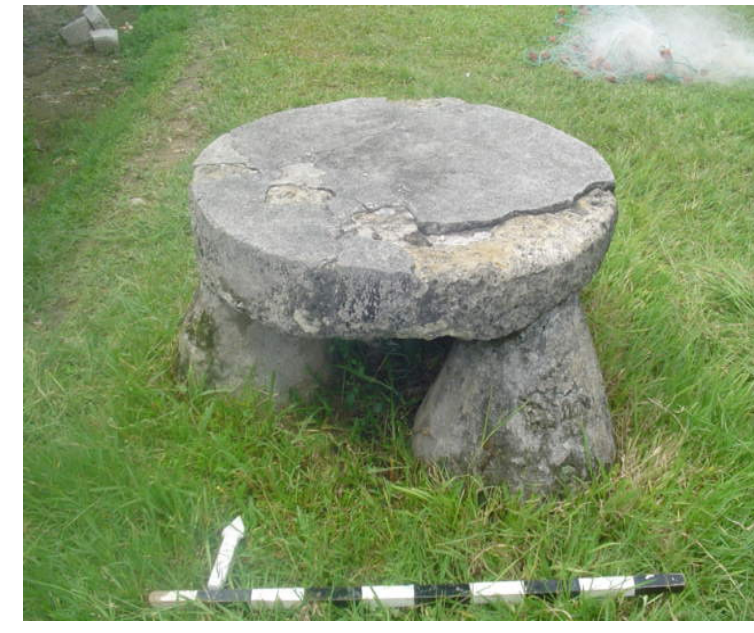

Gambar 3. Dolmen Batu Meja, Desa Nolloth,

Kec. Pulau Saparua, Kab. Maluku Tengah, Propinsi Maluku

(Sumber : Dokumen Balai Arkeologi Ambon, 2008)

Proses ini merupakan rangkaian struktural fungsional yang dikatakan oleh malinowski sebagai organisme yang saling membutuhkan dan bergantungan satu dengan yang lain, yang mempunyai sub-sub sistem yang dapat memperbaiki ketika sistem itu rusak atau lapuk. Hasil penelitian megalitik dolmen di Maluku Tengah disimpulk bahwa permukiman lama/kampung tua berada di posisi ketinggian (dataran tinggi), dengan bukti arkeologis pendukung lainnya seperti sisa-sisa hasil aktifitas manusia, yaitu pecahan fragmen keramik, pecahan gerabah. Masyarakat pendukung megalitik sangat menghormati arwah leluhur, sehinggga hubungan baik antara arwah leluur dan masyarakat pendukungnya sangat dijaga dan dilestarikan. Gunung (dataran tinggi) dipandang sebagai kosmos masyarakat megalitik di Saparua (Salhuteru, $2008: 20$ 24)

Permukiman lama dan dolmen mempunyai kesatuan sistim antara satu dengan yang lain, yaitu bagaimana kedudukan antara manusia dan alam serta kebutuhan untuk bertahan hidup. Satu sisi manusia butuh lokasi untuk tinggal, satu sisi alam menyediakan, satu sisi pula pengetahuan manusia berkembang dengan keberadaan dolmen. Dengan kata lain equilibrium

(keseimbangan) sebab perdagangan di Nusantara Tim dan Kepulauan Maluku masuk jalur pelayaran internasional dan nasional (Harkatiningsih, 2010: 540).

Berikut dapat dilihat pada gambar 4 entang struktur sumberdaya arkeologi di Kepulauan Maluku.

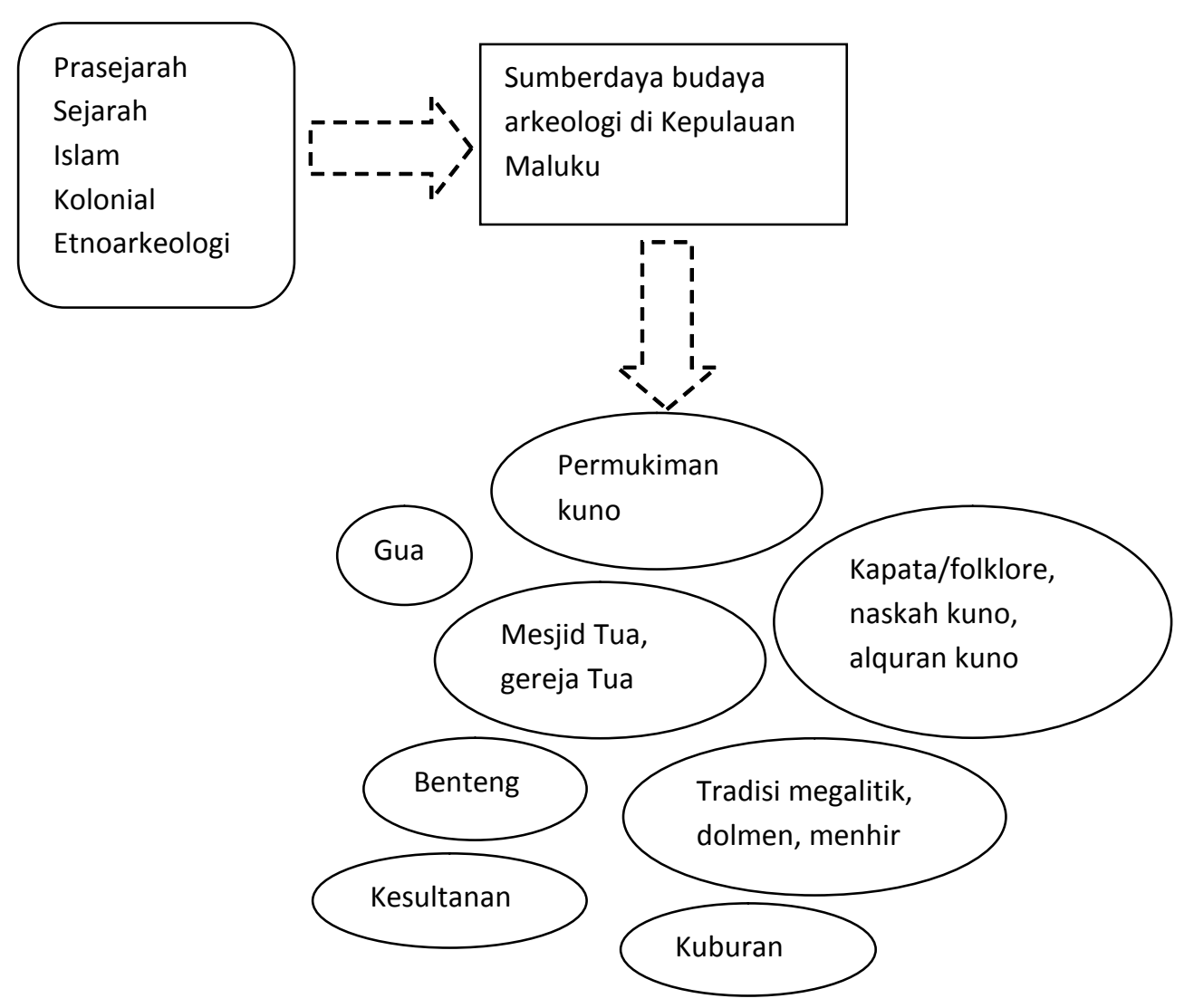

Gambar 4. Struktur Sumberdaya Arkeologi di Kepulauan Maluku

Dari gambar di atas dapat dilihat bahwa tinggalan-tinggalan arkeologi di Kepulauan Maluku mendominasi semua aspek arkeologi, diantaranya permukiman kuno, dolmen, menhir, tradisi megalitik, kesultanan, benteng, kapata/folklore, gua. Tinggalan arkeologi tersebut merupakan rangkaian budaya secara holistik, tanpa meninggalkan satu sama yang lain. Dari struktur sistem tinggalan arkeologi, maka corak, citra, profil substansi lapisan budaya masa lalu, sekarang dan masa akan datang di Kepulauan Maluku dapat direkonstruksi.
Seperti halnya dengan makhluk-makhluk hidup lainnya, manusia harus selalu menjag hubungan adaptasi dengan lingkungan dan ekosistemnya. Layaknya manusia, lingkungan dan kebudayaan sumberdaya arkeologi haru sejalan dengan sesuai dinamika lapisan budaya. Tinggalan-tinggalan arkeologis yang ada akan dilakukan penelitian oleh para peneliti luar negeri maupun dalam negeri ehingga keseimbangan struktur sumberdaya budaya arkeologi senantiasa pada posisinya Konteks sistem adalah lingkungan budaya yang masih berlangsung. Dalan konteks ini sumberdaya budaya masih berperan aktif dan dipergunakan oleh masyarakat. Konteks arkeologis adalah lingkungan tempat sumberdaya budaya yang sudah tidak dipergunakan sama sekali, sehingga lebih tepat disebut sumberdaya arkeologi berdasarkan hal tersebut, konteks pertama bagi arkeologi di Kepulauan Maluku masih terpelihara dengan baik, contohnya komunitas 
tradisional orang Huaulu dan Nuaulu di Pulau Seram. Sistem nilai budaya mereka sangat terjaga dengan baik, sehingga nilai sosia budaya masih terpelihara sekalipun dinamika perkembangan dunia tetap jalan seiring waktu. Untuk konteks kedua, tinggalan arkeolog memang dipandang sebagai sesuatu benda mati, tetapi nilai dibalik benda mati itu sendiri sangat besar bagi kepentingan makhluk hidup Maluku ke masa-masa mendatang dan Indonesia umumnya.

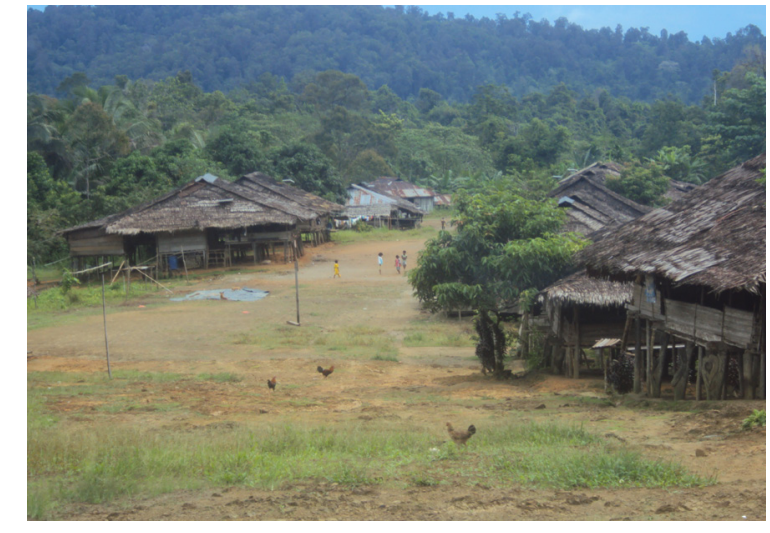

Gambar 5. Permukiman Tradisional Orang Huaulu Seram Utara, Kabupaten Maluku Tengah Propinsi Maluku

(Sumber : Dokumen Balai Arkeologi Ambon, 2008)

Interaksi Simbolik: Tinggalan Arkeologi Sebagai Kesatuan Sistem Sosiat Bu Perspektif interaksi simbolik berusaha memahami perilaku manusia dari sudut pandang subjek. Perspektif ini menyarankan bahwa prilaku manusia harus dilihat sebaga proses yang memungkinkan manusia membentuk dan mengatur prilaku merek dengan mempertimbangkan ekspektasi orang lain yang menjadi mitra interaksi mereka. Menurut teoritis interaksi simbolik, kehidupan sosial pada dasarnya adalah interaksi manusia dengan menggunakan simbol-simbol (Mulyana 2010 : 70-71) Berdasarkan pemahaman tersebut, maka secara eksplisit sumberdaya budaya arkeologi adalah interprestasi kebudayaan manusia dahulu, struktur dasar kebudayaan manusia dalam menciptakan gagasan-gagasan, ide untuk keberlanjutan masyarakat manusia yang akan datang.

Mulyana memberikan esensi interaksi simbolik adalah suatu aktifitas yang merupakan ciri khas manusia, yakn komunikasi atau pertukaran simbol yang diberi makna (Mulyana, 2010 : 68). Tinggalan arkeologis di Kepulauan Maluku, secara eksplisit telah terjadi fenomena interaksi antara manusia dan alam serta nilai-nilai sosial budayanya. Bachtiar menyebutkan dalam suatu kebudayaan terdapat 4 (empat) perangkat simbol yang berbeda (Munandar, 2010: 71). Keempat perangkat simbol tersebut, yaitu :

1. Simbol-simbol konstitusif, biasanya terbentuk dalam wujud kepercayaankepercayaan dan biasanya merupakan inti dari agama.

2. Simbol-simbol kognitif yang membentuk ilmu pengetahuan.

3. Simbol-simbol penilaian moral yang membentuk nilai-nilai dan aturan aturan

4. Simbol-simbol pengungkapan perasaan atas simbol-simbol ekspresif.

Benteng sebagai salah satu peninggalan arkeologi, secara simbolik merepresentasikan bentuk, kemegahan, kekuasaan dalam sosial budaya bermasyarakat pada waktu itu, dan implikasi pada waktu sekarang bahkan waktu-waktu mendatang. Inti dari keadaan subjektif dan objektif adalah bagaimana benteng sebagai bangunan melahirkan pemahaman dan persepsi baru atas kehidupan masyarakat manusia kepulauan Maluku. Hal tersebut dapat dilihat pada penduduk Kota Ambon yang cikal bakal lahirnya adalah dari Benteng Victoria, yang mana penduduk menetap dan tinggal di sekita benteng, lama Kota Ambon yang terbagi dalam beberapa territorial (lambang kekuasaan penjajah belanda). Goodenough (Dilistone 2002 19) mengatakan simbol adalah barang atau pola yang, apapun sebabnya, bekerja pada manusia, dan berpengaruh pada manusia, melampui pengakuan semata-mata tentang apa yang disajikan secara harafiah dalam bentuk yang diberikan itu.

Contoh lain, situs Gua Hatuurang yang berada di daerah Pulau Seram Bagian Barat, tepatnya di Desa Hatusua. Menurut budaya tutur masyarakat setempat bahwa dulu Hatuurang adalah lokasi kompleks manusia Seram Barat bermukim. Dari sisi arkeologi situs Hatuurang memang sangat komperhensif untuk menetap. Karena dekat dengan sumber bahan makanan, dan dekat juga laut. Oleh Soejono mengatakan bahwa manusia prasejarah, khususnya Plestosen akhir sampai awal Holosen, dalam mempertahankan hidupnya masih bergantung pada ketersediaan lingkungan alam sekitarnya. Di Asia Tenggara, kehidupan gua (cave) atau ceruk (Rock shelter) mencapai puncaknya pada kala Holosen. Dikatakan lanjut oleh Heekeren dalam memanfaatkan gua/ceruk sebagai tempat tinggal, manusia saat itu telah mempertimbangkan masak-masak. Tidak semua gua atau ceruk dimanfaatkan sebagai tempat tinggal (tempat bermukim). Dari aspek keletakan, manusia saat itu cenderung memilih lokasi gua atau ceruk pada daerahdaerah yang menyediakan kebutuhan pokok, seperti sumber bahan makanan aquatic atau non aquatic yang dianggap menguntungkan dari segi subsistensinya (Asikin, 2012: 1).

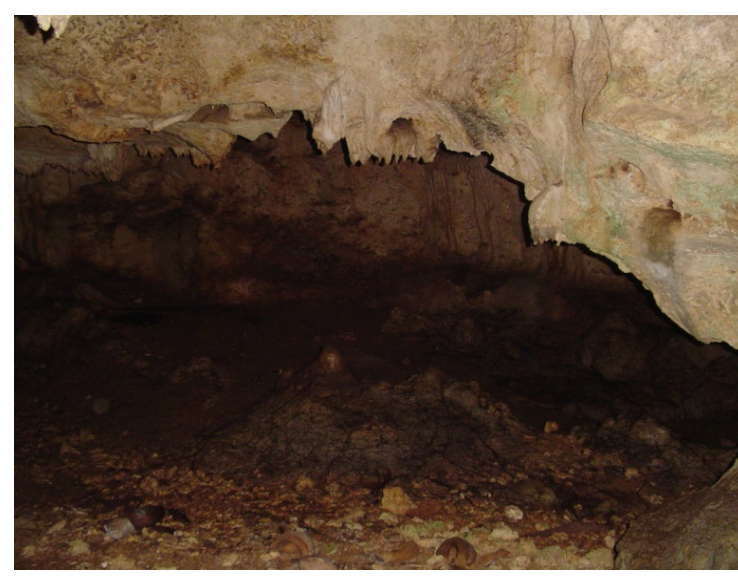

Gambar 6. Gua prasejarah Hatuurang Negeri Hatusua, Kab. Seram Bagian Barat, Propinsi Maluku Sumber : Dokumen Balai Arkeologi Ambon, 2009)
Dolmen, menhir, negeri lama permukiman lama bagian integral dari sebuah sistem sosial budaya. Ketiga tinggalan arkeologis ini sangat erat kaitannya dengan masyarakat adat di Kepulauan Maluku. Seperti yang telah dijelaskan sebelumnya sifat ketiga tinggalan arkeoloogi ini temporal parsial (saling keterkaiatan antara satu dengan yang lain). Mesjid dan gereja tua, secara eksplisit melambangkan kekuasaan pad waktu itu serta perkembangan masyarakat dari fase ke fase. Masjid identik dengan Islam, seperti yang kita ketahui bahwa perkembangan Islam di Indonesia umumnya dan Kepulaun Maluku khususnya telah berlangsung abad-abad lamanya sebelum masuknya bangsa penjajah (gereja). Pada dasarnya Islam di Maluku, dapat ditelusur dengan tinggalan-tinggalan arkeologis, diantaranya arsitektur, pola sebaran, ajaranya dan budaya tutur atau etnografi (Handoko, 2011 : 27- 40). Interprestasi makna dar tinggalan arkeologi telah memaknai substnasi nilai, norma, falsafah dan bahkan seluruh aspek sosial budaya didalamnya. Implikas pemknaan tinggalan arkeologi adalah tidak ain memberikan gambaran perspektif erhadap umat manusia (masyarakat) bahwa konstruksi awal peradaban manusia memang seperti ini, dan untuk itu diperlukan pemahaman dan penelusuran lebih ata gagasan-gagasan, dan ide kebudayaan Budaya benda bendawi tinggalan arkeologi Islam sebagai representase pemaknaan simbol daripada nilai sosial budaya manusia.

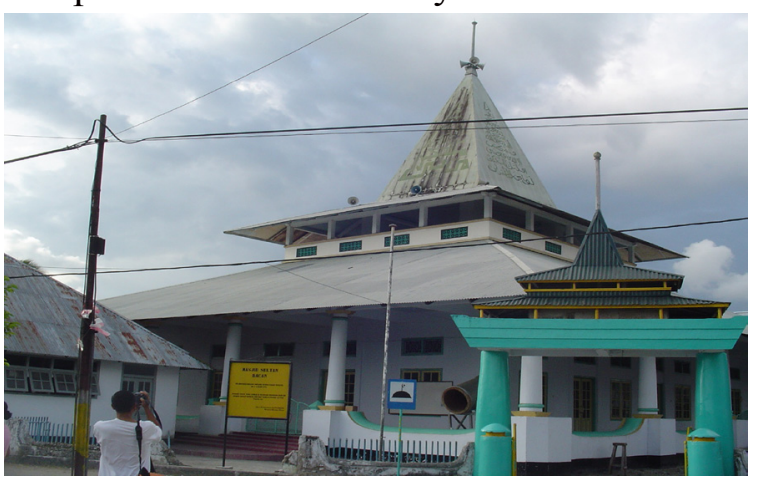

Gambar 7. Mesjid di Pulau Bacan, Propinsi Maluku Utara

Sumber : Dokumen Balai Arkeologi Ambon, 2009) 
Interprestasi simbolik mesjid dan pendukungannya memberikan konstribusi besar bagi pengembangan arkeologi Maluku ke masa-masa mendatang. Sebagian masyarakat masih memegang peranan dan kedudukan dalam khasanah budaya. Dari tinggalan arkeologi islam, yaitu mesjid, arsitekstur, alquran kuno dan sebagainya banyak memberikan pengembangan pendidikan dan kebudayaan khususnya dalam bidang arkeologi.

\section{PENUTUP}

Kepulauan Maluku merupakan salah satu territorial kepulauan di Indonesia, merupakan dua wilayah, yaitu Maluku dan Maluku Utara. Sejalan perkembangan zaman dari masa ke masa merekonstruksikan peninggalan sumberdaya budaya yang kaya, baik secara ilmiah, sosial budaya, politik bahkan ekonomi. Tinggalan-tinggalan arkeologis (sumberdaya budaya) di Kepulauan Maluku, antara lain : dolmen, gua, benteng, negeri lama/permukiman lama, menhir, kesultanan, kapatalfolklore.

Adapun tinggalan arkeologis dimaksud adalah struktur dasar pemahaman akan kebudayaan di Kepulauan Maluku. Secara individual, kelompok merepresentasikan interaksi; antara manusia dengan alam lingkungannya, sintegrasi; kausalitas identitas, serta identitas masyarakat manusia di Kepulauan Maluku itu sendiri.

$$
* * * * *
$$

\section{DAFTAR PUSTAKA}

Belwood, Peter. 2000. Prasejarah Kepulauan Indo-Malaya. Edisi Revisi. Jakarta. PT. Gramedia Pustaka Utama.

Dilistone, F. W. 2002. The Power Of Symbols. Jogjakarta. Kanisius.

Handoko, Wuri. 2011. Jejak Islam Tionghoa Di Wilayah Maluku. Kapata Arkeologi (Jurnal Arkeologi Wilayah Maluku dan Maluku Utara) Hal 27-40 Vol 7. No. 12/ Juli. Ambon: Balai Arkeologi Ambon.
Harkantiningsih, Naniek. 2010. Keramik Dalam Konteks Pertumbuhan Niaga di Nusantara Bagian Timur. Pentas Ilmu Di Ranah Budaya. Pustaka Larasan. Denpasar Bali. Hal 540-553.

Huliselan, Mus. 2009. Perdagangan Internasional Pengaruhnya Terhadap Perubahan Sistem Nilai Budaya Masyarakat Maluku. Makalah disampaikan dalam Seminar Nasional Sail Banda Ambon. Ambon: Balai Arkeologi Ambon.

Koentjaraningrat. 1987. Sejarah Teori Antropologi I. Cetakan Pertama. Jakarta. UI Press.

Latifundia, Effie. 2007. Permukiman Pada Masa Lampau di Sepanjang DAS Ciberang Kecamatan Sajira, Kabupaten Lebak, Propinsi Banten. Permukiman, Lingkungan dan Masyarakat. IAAI Komda Jawa Barat - Banten. 17-26.

Mulyana, Deddy. 2010. Metodologi Penelitian Kualitatif. Bandung. PT. Remaja Rosdakarya.

Munandar, Agus Aris. 2010. Simbolisme Kepurbakalaan Megalitik Di Wilayah Pagar Alam, Sumatra Selatan. Dalam Pentas Ilmu Di Ranah Budaya. Pustaka Larasan. Denpasar Bali. Hal 68-98.

Nuraini, Asikin Indah. 2012. Sistem Kubur Penghuni Gua Kidang Hunian Masa Prasejarah Kawasan Karts Todanan, Blora. Berita Penelitian Arkeologi Jogjakarta. No 26. Hal 1-19. Jogjakarta: Balai Arkeologi Jogjakarta.

Ririmase, Marlon. 2011. Perahu Sebagai Simbol Di Maluku Tenggara (Sebuah Pengantar). Kapata Arkeologi (Jurnal Arkeologi Wilayah Maluku dan Maluku Utara). Balai Arkeologi Ambon. Hal 1-17 Vol 7. No. 12/Juli. Ambon: Balai Arkeologi Ambon.

Sahulteru, Marlyn. 2008. Laporan Penelitian Arkeologi Kajian Keruangan dan Pesebaran Megalitik di Pulau Saparua Kabupaten Maluku Tengah. Ambon: Balai Arkeologi Ambon. 